(C) 2015, Elsevier. Licensed under the Creative Commons AttributionNonCommercial-NoDerivatives 4.0 International http://

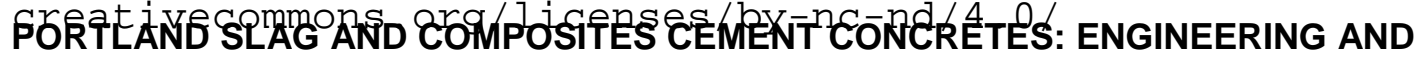 DURABILITY PROPERTIES
}

\author{
Şevket Can Bostancı*, Mukesh Limbachiya, Hsein Kew \\ School of Civil Engineering \& Construction, Kingston University, London KT1 2EE, UK \\ sevketbostanci@yahoo.com, \\ School of Civil Engineering \& Construction, Kingston University, London KT1 2EE, UK \\ T: +447540493305
}

\begin{abstract}
The use of different cementitious main constituents is permitted within the BS EN 197-1 for use in concrete construction. The selection of cement types made depends on requirement of enhanced engineering and durability properties of concrete as well as exploiting potential for producing environmentally friendly concretes for practical applications. The main results of a laboratory experimental programme aimed at examining the performance of Portland-slag and composite cement (CEM II/B-S, CEM II/B-M, CEM V/A and $\mathrm{CEM} V / \mathrm{B}$ ) concrete mixes designed for equivalent 28-day compressive cube strengths of 40 and $50 \mathrm{~N} / \mathrm{mm}^{2}$ are reported in paper. The effect of up to $30-50 \%$ of ground granulated blast-furnace slag (GGBS) and its' combination with the silica fume (SF) and fly ash (FA) within the BS EN 197-1 permitted limits- on fresh, engineering and durability properties have been established and its suitability for use in a range of practical applications was assessed.

The loss of workability in all mixes was of a uniform nature and was found to be more for CEM V/B concrete mixes. Studies of hardened concrete properties, comprising bulk engineering properties (compressive cube and cylinder strength, flexural strength, drying shrinkage) and durability (initial surface absorption, carbonation rates) showed enhanced performance for Portland-slag and composite cement concrete mixes of equivalent strength, except resistance to carbonation.
\end{abstract}

Keywords: Carbonation, drying shrinkage, durability, fly ash, ground granulated blast-furnace slag, initial surface absorption, mechanical properties, Portland cement, silica fume

\section{Bullet points:}

Lower $w / c$ ratios did not have any influence on minimizing the early strength loss for equivalent 28-day strength concretes.

Drying shrinkage results showed that the contribution of pozzolanic reactions for Portlandslag and composites cement concretes takes place after 14 days.

Portland-composite cement concretes (PC+GGBS+SF) with higher w/c ratio showed improved pore structure.

Carbonation resistance was observed to be linked with the loss of workability over time. 


\section{INTRODUCTION}

The European Standard for common cements, BS EN 197-1 [1] offers a broad range of cement constituents for concrete production with opportunities for utilising many of the industrial by-products. Thus, this offers environmental benefits to concrete construction, and a real potential for contributing in achievement of sustainable development goals. Amongst the cement types permitted within this standard is the use of Portland slag cements containing 21-35\% GGBS (Type II/B-S) and composite cements containing: (i) $18-30 \%$ GGBS with the same amount of pozzolana with fly ash and up to $5 \%$ minor additional constituents (Type V/A), and (iii) 31-50\% GGBS with the same amount of pozzolana with fly ash and up to $5 \%$ minor additional constituents (Type V/B). However, lack of full scientific data on the engineering and durability performance of such concrete mixes limits its full application.

The review of technical data suggests, GGBS cement concretes have improved the fresh properties of concrete [2-3]. Extensive research carried out on the use of GGBS in combination with PC and other cementitious constituents in concretes indicated that lower early compressive strength due to slower hydration rate of GGBS [2-12]. The lower early strength reported in the existing studies have become more obvious as the replacement levels, on mass basis, increases [2, 8]. In addition, Teng [3] and Qiang [13] stated that the difference in early age compressive strength becomes smaller at lower water/cement $(\mathrm{w} / \mathrm{c})$ ratios. However, this lower strength development was monitored to be compensated with the prolonging curing periods [2-3, 5-8, 10-12]. However, there is no agreement on the replacement level of GGBS in blended cement concrete for optimum performance concrete. According to Johari [2], maximum long term strength was obtained with an optimum level of $20 \%$. Similar finding was noted by Qiang [13] that 15\% and 30\% GGBS replacement levels gives better compressive strength at post 28 days. Khatri [6] also stated that $35 \%$ GGBS provides better compressive strength at 28 days. In addition to these, Akçaözoğlu [4] stated that use of $50 \%$ GGBS replacement in mortar can slightly improve compressive strength at 28 days. Moreover, slightly improved and comparable results were obtained by Güneyisi [8] for $40 \%$ and $60 \%$ replacement level of GGBS. Studies carried out by Khatri [6] and Berndt [12] with $70 \%$ slag replacement in binary blend cement and $65 \%$ GGBS with silica fume (SF) in ternary blend cement concretes respectively indicated improved compressive strength at longer ages. Gesoğlu [14] stated that use of GGBS in ternary blend cement concrete with another mineral admixture fly ash (FA) with replacement levels of $10 \%$ for both admixtures provided the best performance strength at 28 days. Güneyisi [8] also studied GGBS in ternary blend with SF and FA and stated comparable or improved results monitored for GGBS + SF blend cement concretes regardless the increase in the replacement level (15\% GGBS + 5\% SF, 30\% GGBS + 10\% SF, 45\% GGBS + 15\% SF). However, GGBS blend with FA resulted in lower compressive strengths and 10\% GGBS $+10 \%$ FA blend cement concretes indicated the best results at both 28 and 90 days.

Previous studies have shown that slag utilization enhances drying shrinkage of concrete at longer ages. Akçaözoğlu [4] stated that 50\% GGBS replacement demonstrated comparable performances up to 90 days but showed reduction after 90 days. In addition to this, Qiang [13] observed that slag cement concretes were investigated to develop shrinkage quickly within 40 days as the slag replacement increases (45\%). Qiang [13] also reported that slag utilization has slight influence on concretes with lower w/c ratio (0.35). Güneyisi [8] reported that as the replacement level increases the drying shrinkage decreases. This reduction is higher in ternary blend cement $(P C+G G B S+S F)$ concretes. Jianyong [15] also 
defined that binary (PC+GGBS) and ternary (PC+GGBS+SF) blend cement concretes could reduce drying shrinkage significantly.

Existing literature on the slag cement concretes has indicated reduction in the carbonation resistance [4, 7, 16-18]. Hui-sheng [7] stated that carbonation resistance reduces as the slag content $(15 \%, 30 \%, 45 \%$ and $60 \%)$ increases for the same $\mathrm{w} / \mathrm{c}$ ratio. Similar findings were observed by Younsi [19] and Borges [20] with the slag contents up to $75 \%$ and $90 \%$ respectively leads to reduction in the carbonation resistance. In contrast, Qiang [13] stated that concrete with 15\% slag content indicated better resistance whereas lower resistance monitored by $30 \%$ slag replacement. However, previous studies [7, 17, 19 20] reported that increasing the binder content of slag results in lower carbonation depth comparing to lower binder contents. Akçaözoğlu and Atiş [4] reported that there is a relation between carbonation resistance and loss of workability.

The effect of slag as substitute to PC with various replacement levels in Portland-slag and Portland-composites cements on the performance of concretes is of significant interest as far as the mechanical and durability parameters are concerned. However, the results led to uncertainty on the optimization of slag content for the optimum performance for slag cement concrete. This paper gives a part of extensive study carried out a range of engineering and durability properties of concretes having similar 28-day design strengths made with binary and ternary blended BS EN 197-1 cements (and natural aggregates). These concretes were designed with various proportions of GGBS as a partial substitute of PC, different water/cementitious content $(\mathrm{w} / \mathrm{c})$ ratios and total cementitious contents. On the other hand, there is also a potential for producing concretes with reduced environmental footprint for practical applications as the PC content is replaced with more environmentally friendly additional cementitious constituents.

\section{EXPERIMENTAL AND TESTING PROGRAMME}

\subsection{Materials}

In order to promote wider use of Portland-slag and composite cements concrete, a range of BS EN 197-1 cement types with limited data on its influence on the engineering and durability properties of concrete were selected. These include; CEM II/B-S (35\% GGBS), CEM II/B-M (30\%GGBS \& 5\%SF), CEM V/A (30\%GGBS \& 30\%FA), CEM V/B (50\%GGBS \& $30 \% \mathrm{FA}$ ), were used within the framework of cement types covered in BS EN 197-1. Portland-cement (CEM I; 100\% PC) was used as reference, and other main constituents were used as direct replacement of PC. The natural aggregates (NA) used were natural uncrushed Thames valley gravel of $20 \mathrm{~mm}$ maximum size and natural sand of $5 \mathrm{~mm}$ maximum size. Table 1 gives the physical and mechanical properties of natural aggregates used. GGBS was obtained from iron-making production in the UK conforming to BS EN 15167-1 [21]. FA and SF used were conforming to BS EN 450-1 [22] and BS 13263-1 [23] respectively. FA was obtained from Drax coal-fired power station in the UK. SF incorporated was in slurry form including $50 \%$ water and $50 \%$ silica powder. The chemical composition of cementitious materials provided by the manufacturers is presented in Table 2 . Water reducer admixture conforming to BS EN 934-2:2009+A1 [24] was used throughout the study to achieve nominal design slump. 
Table 1 - Physical and mechanical properties of aggregates used

\begin{tabular}{lcc}
\hline \multicolumn{1}{c}{ Properties } & \multicolumn{2}{c}{ Aggregates } \\
\cline { 2 - 3 } & Sand & Gravel \\
\hline Physical (BS EN 1097, part 6) & 1.52 & 1.51 \\
Unit weight $\left({\left.\mathrm{Mg} / \mathrm{m}^{3}\right)}^{\text {Apparent density }\left(\mathrm{Mg} / \mathrm{m}^{3}\right)}\right.$ & 2.75 & 2.60 \\
Water absorption capacity (\%) & 0.70 & 1.65 \\
Fineness modulus & 2.62 & 3.31 \\
Mechanical (BS 812, parts 110- & & \\
112) & - & 18 \\
Aggregate crushing value (\% ACV) & - & 6.5 \\
Aggregate impact value (\% AIV) & 155 & \\
10\% Fines (KN) &
\end{tabular}

Table 2 - Chemical properties of cementitious constituents

\begin{tabular}{ccccc}
\hline Compound & \multicolumn{4}{c}{ Percentage (\%) } \\
\cline { 2 - 5 } & $\mathrm{PC}$ & $\mathrm{FA}$ & GGBS & $\mathrm{SF}$ \\
\hline $\mathrm{SiO}_{2}$ & 19.77 & 50.4 & 36.76 & 94.84 \\
$\mathrm{Al}_{2} \mathrm{O}_{3}$ & 4.90 & 28 & 13.38 & - \\
$\mathrm{Fe}_{2} \mathrm{O}_{3}$ & 2.33 & 9 & 0.37 & - \\
$\mathrm{CaO}$ & 62.56 & 6 & 39.56 & 0.41 \\
$\mathrm{MgO}$ & 2.64 & 1.50 & 7.33 & - \\
$\mathrm{SO}$ & 3.08 & 0.40 & 0.08 & 0.32 \\
$\mathrm{~K}_{2} \mathrm{O}$ & 0.66 & 2.50 & 0.54 & 0.88 \\
$\mathrm{Na}_{2} \mathrm{O}$ & 0.17 & 0.90 & 0.32 & 0.26 \\
Loss on ignition & 1.65 & 4.50 & 0.92 & 1.56 \\
Fineness $\left(\mathrm{m}^{2} / \mathrm{kg}\right)$ & 372 & 280 & 501 & 22700 \\
Density $\left(\mathrm{g} / \mathrm{cm}^{3}\right)$ & 3.14 & 2.28 & 2.92 & 1.4 \\
\hline
\end{tabular}

\subsection{Mix proportions and concrete mix design}

Conventional BRE mix design method [25] was used to produce trial mixes. Mixes were designed to achieve workability between $60-180 \mathrm{~mm}$ and 28-day cube strength of 40 and 50 $\mathrm{N} / \mathrm{mm}^{2}$. The free water contents of these mixes were modified according to type of the cementitious constituents used. Additional cementitious constituents (GGBS, FA and SF) were used by blending with CEM I, PC, at the mixer for CEM II and CEM V cement concretes. To achieve equivalent 28-day cube strength as CEM I concrete, the w/c ratios and total cementitious contents were altered depending upon the relationship between the compressive cube strength and the $\mathrm{w} / \mathrm{c}$ ratios of trial mixes. Detailed summary of mix proportions used are given in Table 3. It is noteworthy to mention that SF values given is in slurry form, thus half of the SF used was deducted from the free water content. When SF used, free water/cement ratio was determined by adding free water content and half of the SF used and divided by cementitious content including binders but half of the SF used.

The initial mix was a control mix with PC only specified as CEM I and a Portland-slag cement mix was CEM II/B-S (65\%PC-35\%GGBS). Additionally, Portland-composite and composite cement mixes with various combinations of cementitious constituents stated as CEM II/B-M (65\%PC-30\%GGBS-5\%SF), CEM V/A (40\%PC-30\%GGBS-30\%FA) and CEM V/B (20\%PC-50\%GGBS-30\%FA) respectively. 


\subsection{Test Procedures}

Concrete casting and testing was carried out in accordance with BS EN 12350:2000 Parts 1 and 2 [26]. Following concrete production, initial slump was recorded and slump loss was investigated with 30 minutes intervals up to 150 minutes by conducting compacting factor test in order to evaluate the effect of cement types on the retention of concrete workability. All test samples were cured under standard $20^{\circ} \mathrm{C}$ water conforming to BS EN 12390-2 [27] until test age and exposure. Engineering properties (compressive and flexural strengths and drying shrinkage) were established following test procedure described in the relevant British standards. $100 \mathrm{~mm}$ cube and cylinder with $150 \mathrm{~mm}$ diameter and $300 \mathrm{~mm}$ height were cast to determine compressive strength in accordance with BS EN 12390-3. Flexural strength tests were carried on $100 \times 100 \times 500 \mathrm{~mm}$ prism specimens according to BS EN 12390-5. Drying shrinkage samples were cast in metal prisms of $75 \times 75 \times 280 \mathrm{~mm}$ and cured for the first 7 days and stored in a drying environment $\left(22^{\circ} \mathrm{C}\right.$ and $\left.55 \% \mathrm{RH}\right)$ as stated in BS ISO 1920-8 [28]. Tests evaluating durability properties including initial surface absorption and carbonation resistance were also investigated. There were 3 samples tested and averaged at each test age for the different types of tests to demonstrate the performance of ranges of concrete properties. Test ages for the properties investigated are given in table 4 .

Table 4. Age at test for the range of properties considered

\begin{tabular}{cc}
\hline PROPERTY & TEST AGES \\
\hline Compressive strength, $\mathrm{N} / \mathrm{mm}^{2}$ & $1,3,7,28,56,90,180$ and 365 days \\
Compressive cylinder strength, $\mathrm{N} / \mathrm{mm}^{2}$ & 28,56 and 90 days \\
Flexural strength, $\mathrm{N} / \mathrm{mm}^{2}$ & 7,28 and 56 days \\
Drying shrinkage, $10^{-6}$ & Up to 112 days \\
Initial surface absorption, $\mathrm{ml} / \mathrm{m}^{2} / \mathrm{s} \times 10^{-2}$ & 28 days \\
Carbonation resistance, $\mathrm{mm}$ & 13,26 and 52 weeks \\
\hline
\end{tabular}

\subsubsection{Permeation property}

Porosity is one of the important aspects on the durability of concrete. Initial surface absorption test (ISAT) was conducted to evaluate the porosity of concrete mixes by the rate of water penetrating into concrete under a hydrostatic pressure of $200 \mathrm{~mm}$ head that flows 
into capillary suction through a specific known area in accordance with the method stated in BS 1881-208 [29]. 150mm cubes were used to determine ISAT values. Samples were cured in $20^{\circ} \mathrm{C}$ water for 28 days, then oven-dried to a constant weight and left to cool in the laboratory environment prior to test. The contact surface area was sealed to prevent any leakage during the test while testing and evaluation of the volume flow is obtained by measuring the length of flow along the capillary tube with a known dimension. ISAT values were determined after ten minutes (ISAT-10).

\subsubsection{Carbonation}

$100 \mathrm{~mm}$ cubes were used for determining the carbonation. Samples cured in $20^{\circ} \mathrm{C}$ water for 28 days and stored in ambient conditions for at least 14 days to air dry. The specimens were then stored in a carbonation chamber at $20^{\circ} \mathrm{C}$ a nd enriched $4 \%$ carbon dioxide $\left(\mathrm{CO}_{2}\right)$ environment [30] up to 52 weeks. All sides of concrete samples apart from one were coated with epoxy based paint to allow $\mathrm{CO}_{2}$ to penetrate only through the sides. Samples with thicknesses not less than $10 \mathrm{~mm}$ were cut with water-cooled diamond saw and depth of carbonation was measured by spraying phenolphthalein indicator solution (1 $\mathrm{gr}$ phenolphthalein indicator in a solution $70 \mathrm{ml}$ ethanol and $30 \mathrm{ml}$ demineralised water). After spraying, carbonated sections with $\mathrm{pH}$ value of less than 9.2 remains colourless whereas in non-carbonated sections, the colour turns pink as a result of its alkalinity. The carbonation depth indicated by the colourless zone of the concrete and at least three readings along the exposed surface were recorded and the average of the readings was recorded as the carbonation depth. The depths behind the coarser aggregates were ignored.

\section{RESULTS AND DISCUSSIONS}

\subsection{Fresh Properties}

Fresh properties of concrete mixes were observed through slump and loss of workability tests. All mixes achieved target slump of S3 workability class, $60-180 \mathrm{~mm}$, according to BS EN 206-1 [31]. Slump values were ranged between $120-150 \mathrm{~mm}$ and $100-155 \mathrm{~mm}$ for 40 and $50 \mathrm{~N} / \mathrm{mm}^{2}$ design strength concretes respectively. However, these values are not an indication as concretes having different admixture contents were designed for a specific consistency class.

Loss of workability of concretes was investigated by conducting compacting factor test with 30 minutes intervals up to 150 minutes after mixing. Results are given in figure 1(a) and 1(b). The results showed that compacting factor values decreased with the increasing strength. This trend was stated by McCarthy and Dhir [32]. It was also apparent that compacting factor values decreased as the PC content in concrete mix reduced. In addition, it was observed that CEM II cement concretes showed comparable results at some point of the test. This may be due to better dispersion and smooth and dense surface characteristics of GGBS that absorbs less water over time [2]. $40 \mathrm{~N} / \mathrm{mm}^{2}$ design strength CEM II/B-M cement concrete, having the highest $\mathrm{w} / \mathrm{c}$ ratio, demonstrated comparable results as corresponding CEM I concrete which had higher w/c ratio amongst concretes, but $50 \mathrm{~N} / \mathrm{mm}^{2}$ 
design strength CEM II/B-M cement concrete, with slightly lower w/c ratio than CEM I concrete, showed lower performance than CEM I concrete. This supports the fact stated by previous researches $[6,33]$ that fine particle size of SF increases adsorption and requires more water to maintain the fluidity of concrete. CEM V cement concrete demonstrated lower compacting factor values amongst all concretes. This is believed to be due to higher total cementitious content and lower water content, thereby lower w/c ratio, of CEM V cement concretes comparing to other concrete mixes. In addition, it is also believed that FA incorporation in CEM V cement concretes increased the viscosity and diminished the fluidity effect of GGBS.
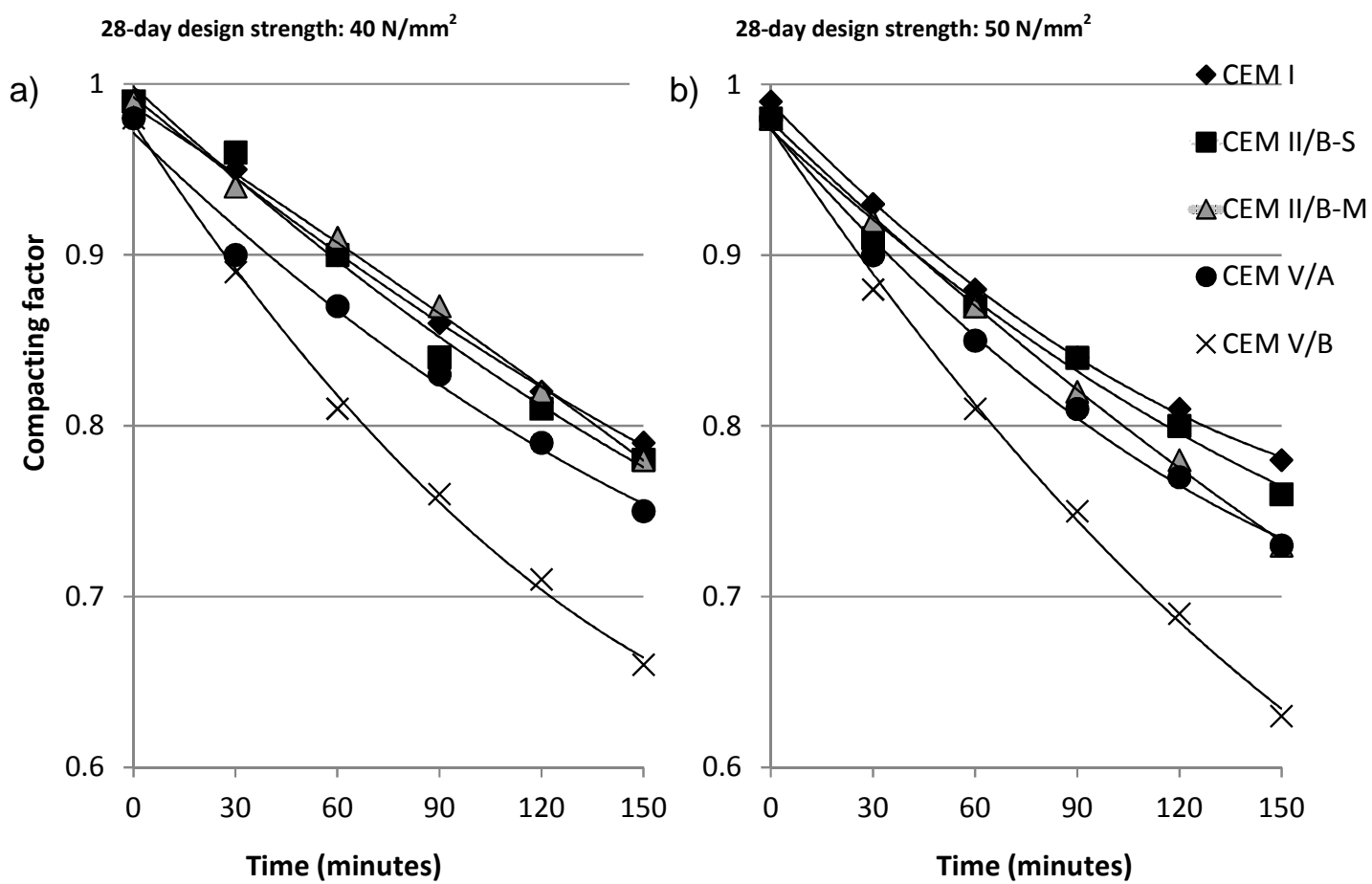

Figure 1. Loss of workability of equal design strength concrete mixes

\subsection{Strength Properties}

Strength development is of concrete strongly related to hydrated cement paste and aggregate content and is of a great indicator for the structural design of reinforced concrete. Therefore, use of slag as a partial substitute to PC could affect the strength development. With regard to that, strength development at early, 1 to 7 days, and longer, post 28-days up to 365 days, ages were taken into account. Moreover, relationship between 28-day cube and cylinder and 28-day and flexural strengths were also investigated. 


\section{Compressive cube strength}

Compressive strength results are given in figures 2(a) and 2(b). Results were in agreement with the previous studies [2-3, 5-10, 13-14] that binary and ternary blend slag cement concretes had lower early strengths comparing to corresponding control mixes even though CEM II and CEM V cement concretes had either similar or lower w/c except $40 \mathrm{~N} / \mathrm{mm}^{2}$ design strength CEM II/B-M cement concrete. Results showed that strength decreases gradually as the replacement level increased as reported earlier [2, 5, 7]. This may be attributed to the fact that PC was substituted by mineral admixtures which lead to reduction in the available $\mathrm{CaO}$ content. Thus, initial formation of $\mathrm{C}-\mathrm{S}-\mathrm{H}$ gel was inhibited in CEM II and CEM V cement concretes [9]. Moreover, reduction in w/c ratio was observed not to have any influence on the minimizing early strength loss in contrast to Teng [3] and Qiang [10]. In addition, SF is known to densify the concrete mix when it is present due to its microfiller effect. However, this effect of SF on the early strength was observed to be diminished which is believed to be CEM II/B-M cement concretes had the lowest total cementitious content, thereby higher w/c ratio amongst all mixes. This was also reported earlier by Bernal and Provis [17] that higher compressive strength was observed for concretes with higher binder content. In general, CEM II cement concretes achieved higher early strengths than CEM V cement concretes at early ages. This may be due to the fact that GGBS has higher $\mathrm{CaO}$ content in comparison to FA (Table 2). Thus, this could make GGBS inclusive mixes to be more reactive than FA inclusive mixes and result in early $\mathrm{C}-\mathrm{S}-\mathrm{H}$ formation for GGBS mixes than FA mixes. All mixes achieved either comparable or better results at 28 days. From onwards, Portland-slag cement concretes indicated higher strength results comparing to PC concretes at all ages. This is coherent with existing studies that the hydration of GGBS is slower comparing to PC, therefore the reactivity of pozzolanic reaction between mineral admixtures and cement paste requires longer curing periods to compensate the early strength loss of concrete [2-7, 9-12].

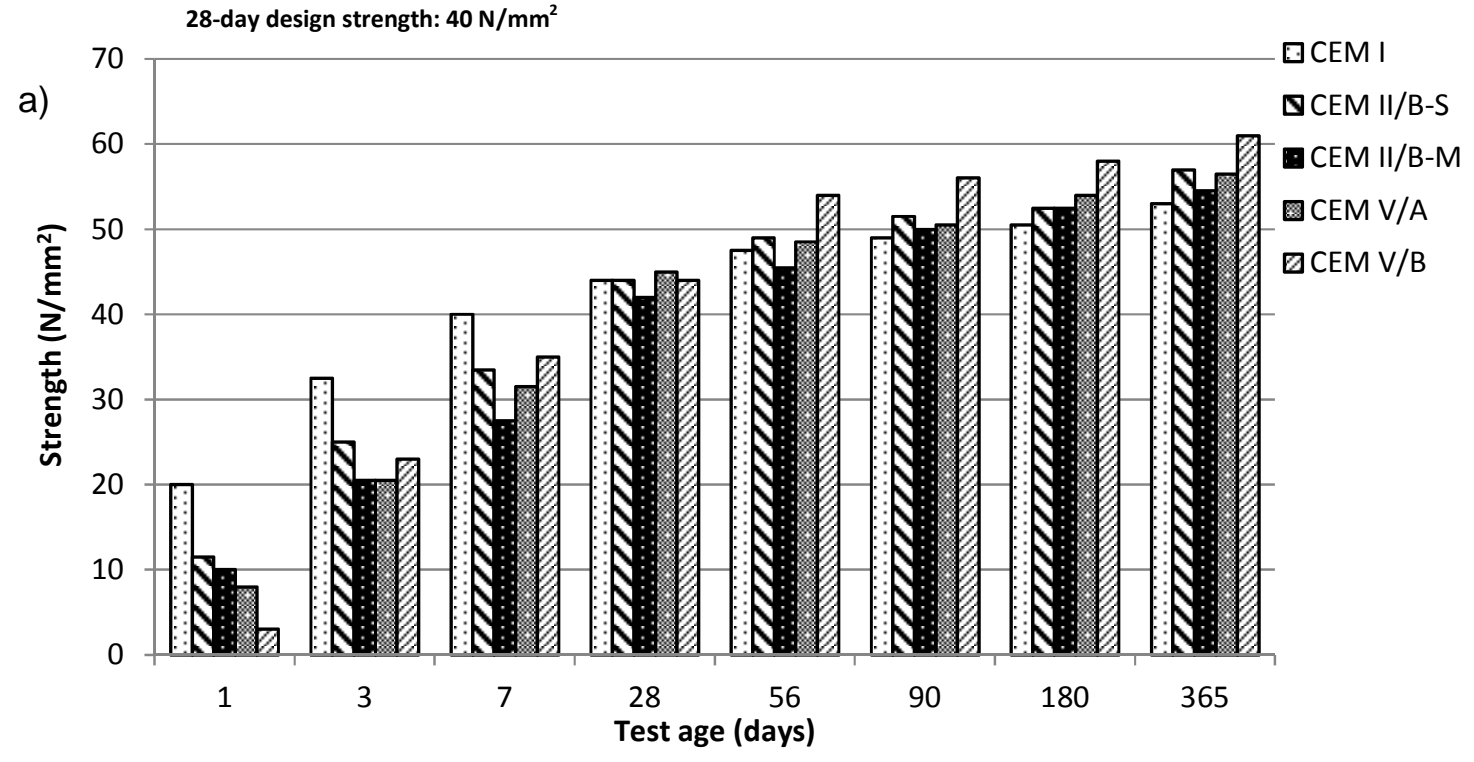




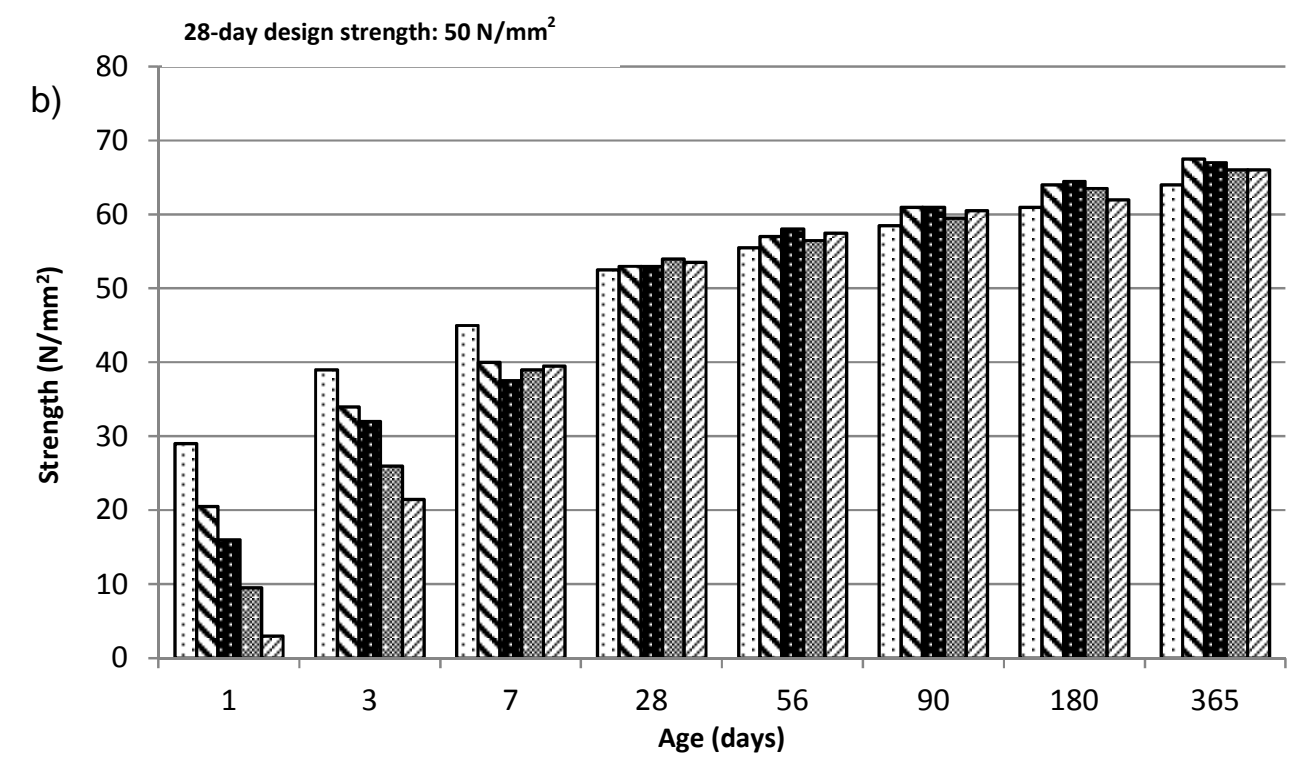

Figure 2. Compressive cube strength development of equal design strength concrete mixes

\section{Compressive cylinder strength}

The relationship between the compressive cylinder and cube strengths at different ages were evaluated in Figure 3. It can be seen that control mix indicated a correlation of 0.97 . In addition, CEM II/B-S and CEM II/B-M showed slightly lower correlation values of 0.93 and 0.94 respectively whilst, CEM V/A cement concretes achieved higher correlation value of 0.98 in comparison to CEM I cement concretes.

The relationship between cylinder and cube compressive strength is of current interest as design to BS EN 1992 is based on compressive cylinder and cube strengths is generally adopted for conformity evaluation and factor of 0.8 is adopted in BS EN 206. The $\mathrm{f}_{\text {cyl }} / \mathrm{f}_{\text {cube }}$ ratios for both design strength concretes are given in Figure 4(a) and 4(b) respectively. It was observed that concretes had lower $f_{\text {cy }} / f_{\text {cube }}$ ratios than design factor of 0.8 which was defined under BS EN 206 except 40 N/mm² design strength CEM II/B-M cement concrete. However, the results were in the range as defined in the previous studies by Bhanja [34] and Nikbin [35] with $f_{\text {cy }} / f_{\text {cube }}$ ratios of $0.71-0.86$ and $0.58-0.94$ respectively. The superior performance of $40 \mathrm{~N} / \mathrm{mm}^{2}$ design strength CEM II/B-M cement concrete can be explained by the extremely fine SF particles improved the matrix between the aggregates and the cement paste. 


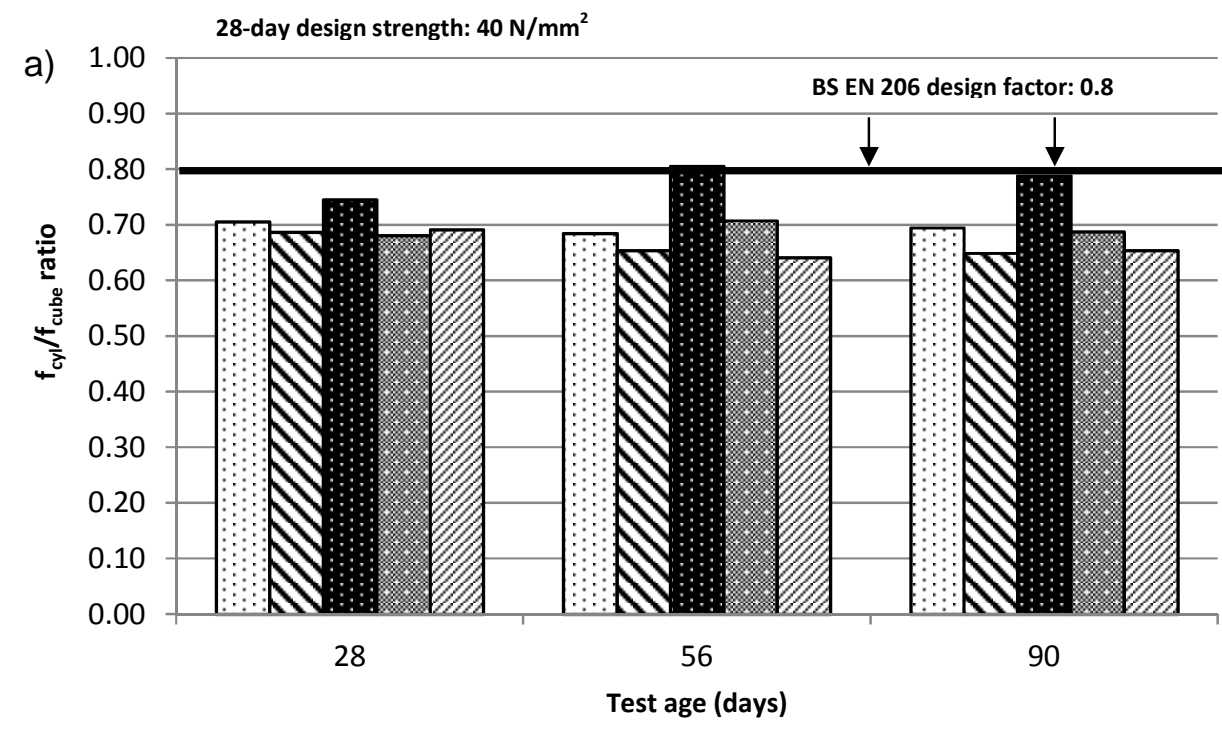

๑CEM I

$\triangle C E M I I / B-S$

a CEM II/B-M 田EM V/A ๑CEM V/B

Figure 3. The relationship between compressive cylinder and cube strengths of equal design strength concrete mixes at 28,56 and 91 days Test age (days) 


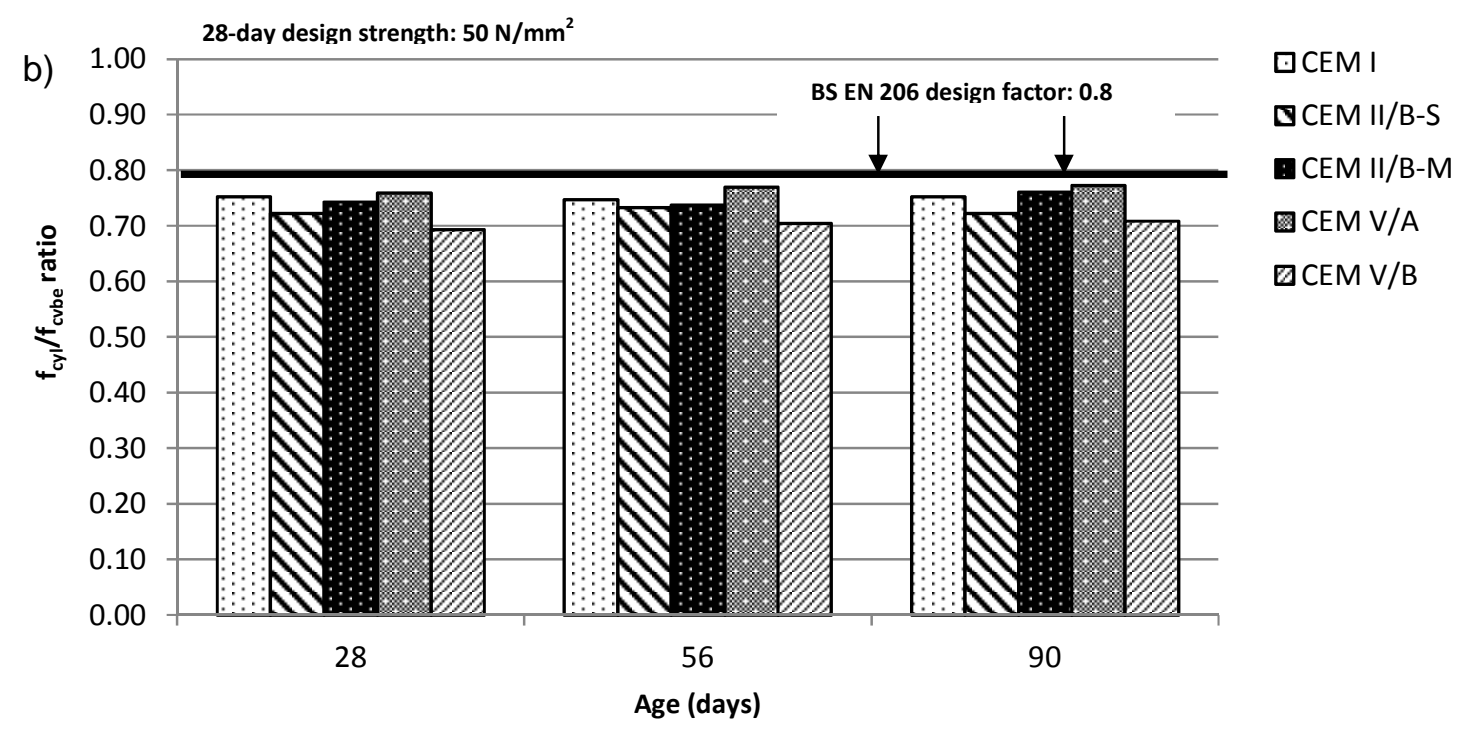

Figure 4. The ratio between compressive cylinder and cubes strengths $\left(f_{\text {cy }} / f_{\text {cube }}\right)$ of concretes

\section{Flexural strength}

Flexural strengths of concrete mixes are given in Figures 5(a) and 5(b). From the results, it can be seen that CEM I cement concretes showed superior strengths at early ages. Similar to compressive cube strength development, it is believed that PC replacement by mineral admixtures reduced the available $\mathrm{CaO}$ content available for mineral admixtures to react and resulted in lower reactivity due to lowering clinker content and thus delayed C-S-H formation. This significant difference was compensated by the contribution of pozzolanic reactions at 28-days. This is coherent with Akçaözoglu and Atiş [4] that flexural strength of concretes was close to PC concrete at 28 days. The improvement in flexural strength was more obvious at 56 days with the extra C-S-H gel provided by prolonging pozzolanic reaction. Slag cement concretes had no adverse effect on the flexural strength of the concrete at 28 days and onwards. In addition, the relationship between the flexural strength and compressive cube strength at 7, 28 and 56 days are given in figure 6. Concrete mixes CEM I, CEM II/B-S and CEM V/A indicated a strong coefficient of correlation, $0.99,0.94$ and 0.98 respectively, whilst CEM II/B-M and CEM V/B had lower coefficient of correlation, 0.89 and 0.87 respectively. 

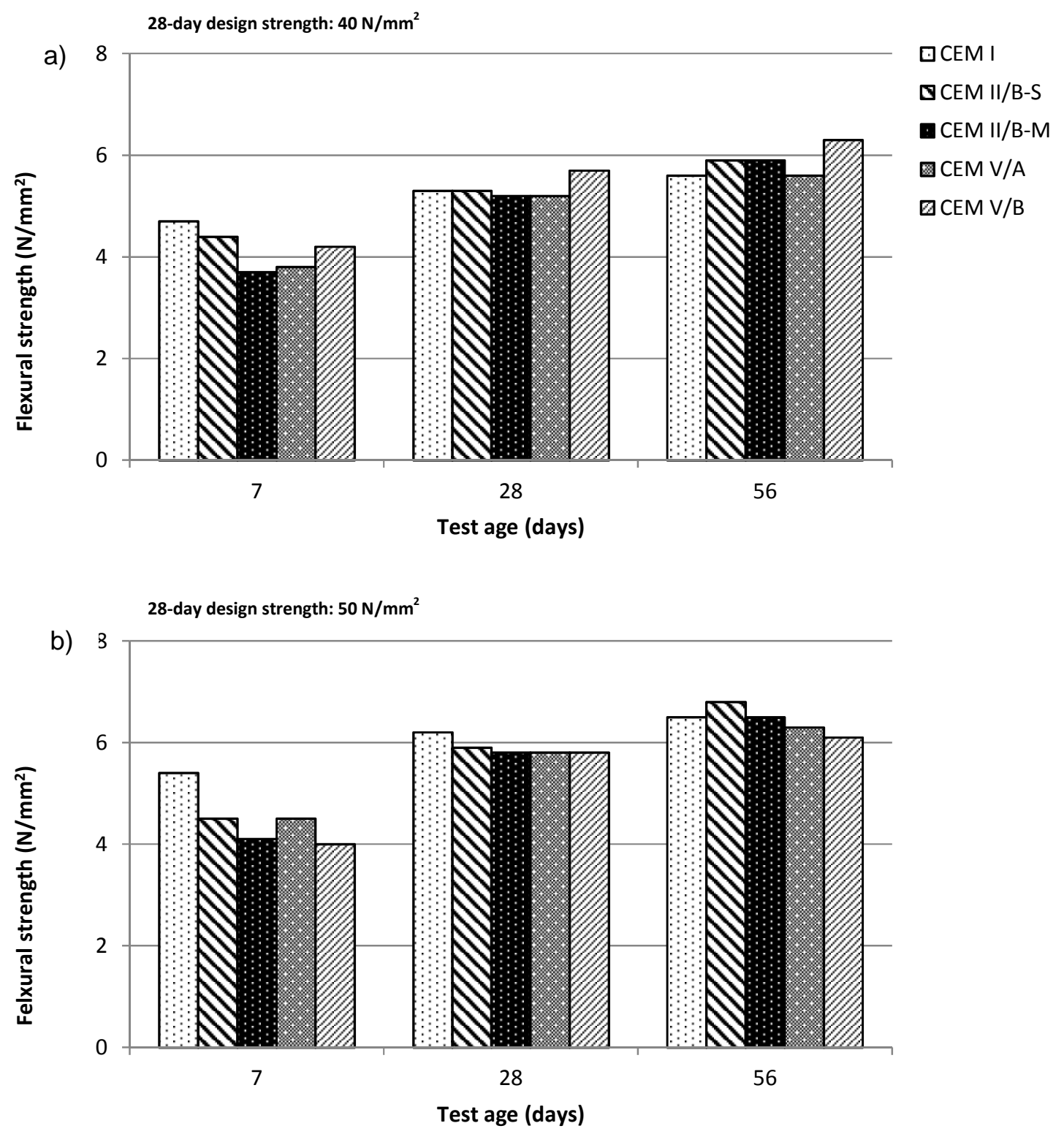

Figure 5. Flexural strength development of equal design strength concrete mixes 
Coefficient of correlation $=\mathrm{R}^{2}$

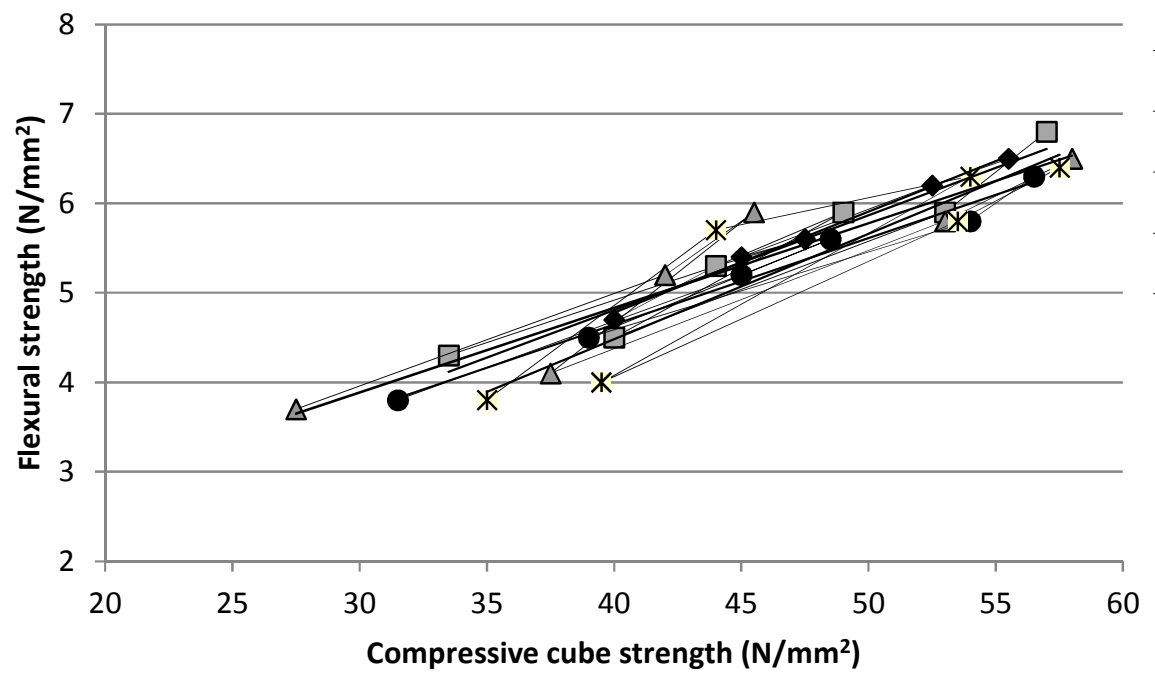

Figure 6. The relationship between flexural and compressive cube strengths of equal design strength concrete mixes at 7,28 and 56 days

\subsection{Drying Shrinkage}

Drying shrinkage is one of the important parameters for concrete slab elements wheras cracks arise as a result of concrete drying shrinkage could negatively affect the load bearing capacity of concrete members.

Figures $7(\mathrm{a})$ and $7(\mathrm{~b})$ show the drying shrinkage development over time for the mixes investigated. General trend observed was in agreement with previous studies [4, 8-9, 13, 16] that drying shrinkage of concretes with mineral admixtures reduced significantly over time. This reduction could be explained by Portland-slag cement concretes had lower water contents as it is a well-known fact that water is the major contributor to the drying shrinkage. However, w/c ratio was observed not to have effect on the shrinkage development of concrete. This is in contrast with Qiang [13] that slag has smaller effect on the drying shrinkage of concrete at lower $w / c$ ratios.

It can be seen from the results that Portland-slag cement concretes showed either comparable or higher shrinkage values at first 14 days. This is in line with Qiang [13] that this higher shrinkage development of slag incorporated concretes is due to hydration of slag takes places slowly therefore water reacts with the cement paste later than in the PC concrete. This is more pronounced at 14 days and onwards. This hypothesis can be supported with compressive and flexural strength results whereas pozzolanic reaction was observed to contribute to strength between 7 days and 28 days for Portland-slag cement concretes. Unlike existing literature, drying shrinkage values showed reduction earlier, 21 days, than reported previously by Akçaözoğlu [4] and Qiang [13]. In addition, CEM II/B-M cement concretes for both design strength concretes were observed to provide higher shrinkage development at 7 days. However, the drying shrinkage developments of CEM II/B$M$ mixes were observed to reduce at 14 days and 21 days for 40 and $50 \mathrm{~N} / \mathrm{mm}^{2}$ design strength concretes respectively. This could be due to the contribution of pozzolanic reactions 
to the hydration which could lessen the free water contents of these mixes. In addition, the results are also in agreement with the previous studies $[6,8,14]$ that the adverse affect of SF was diminished when it is blended with another additional cementitious material in concrete.
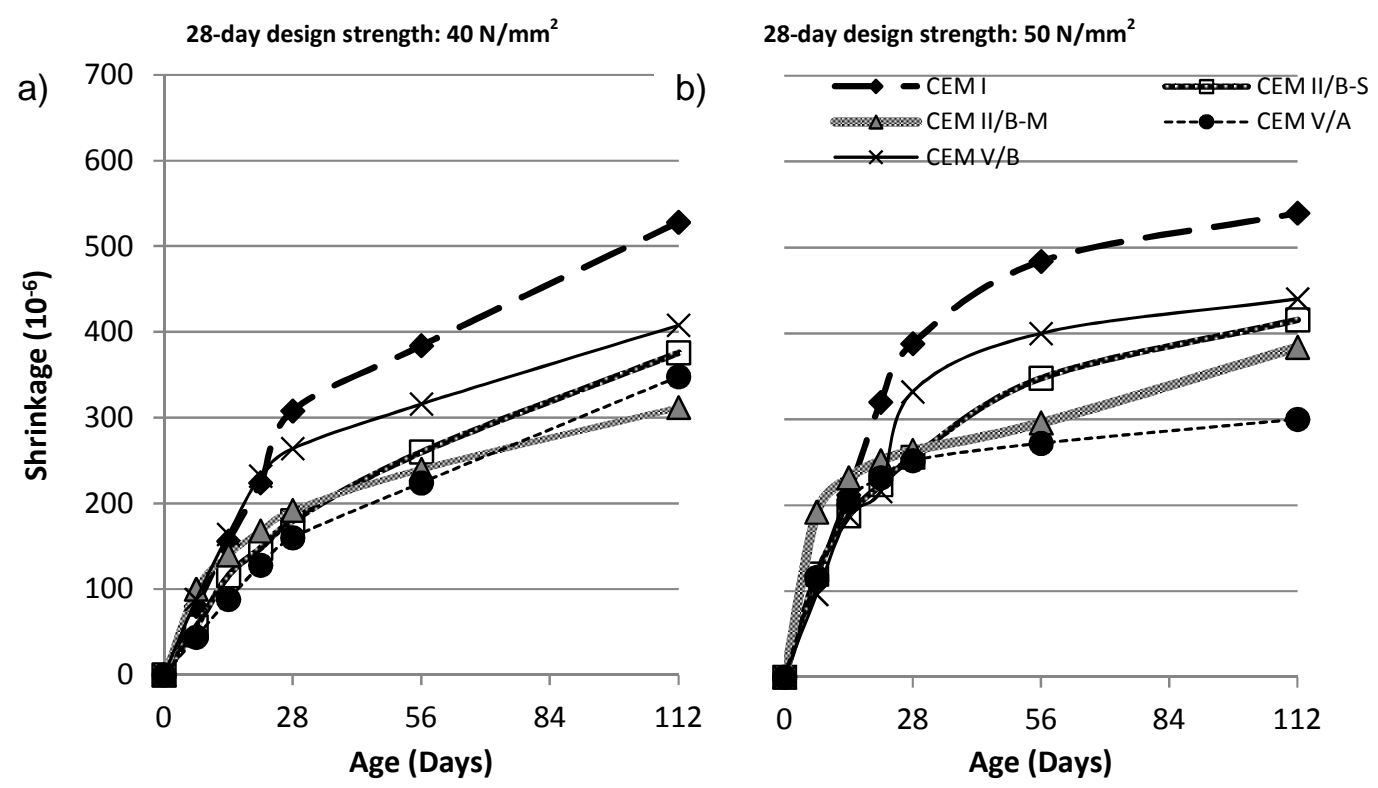

Figure 7. Drying shrinkage values of equal design strength concrete mixes

\subsection{Durability Properties}

\section{Initial Surface Absorption Test (ISAT)}

The ISAT results of concrete mixes after 10 minutes (ISAT-10) and N-value which indicates the rate of decay in the absorption with time results are shown in Table 5 . It can be seen from the results that ISAT-10 and N-value values reduced effectively for CEM II and CEM V cement concretes for the same design strength. Results showed a dramatic reduction due to the fact that $\mathrm{w} / \mathrm{c}$ ratios of CEM $\mathrm{V}$ cement concretes decreased as the total cementitious contents increased. This is believed to result in denser matrix for CEM $\mathrm{V}$ mixes compared to CEM I and CEM II/B mixes. However, CEM II/B cement concretes with similar or higher w/c ratios due to lower total binder content also resulted in significant reduction. This may be attributed to finer characteristics of GGBS and SF particles improved the pore structure of concretes. It is noteworthy to mention that for the same cement type ISAT-10 values increased as the compressive cube strength increases except CEM II/B-M cement concretes which is in contrast with the finding stated by Seddik and Limbachiya [36] that increase in the compressive strength lowers the ISAT-10 values. This could be strongly linked with the increased SF content of $50 \mathrm{~N} / \mathrm{mm}^{2}$ design strength CEM II/B-M mix compared to $40 \mathrm{~N} / \mathrm{mm}^{2}$ design strength CEM II/B-M mix improved concrete pore structure. 


\section{Carbonation Resistance}

Carbon dioxide $\left(\mathrm{CO}_{2}\right)$ present in the atmosphere penetrates into concrete and dissolves in the pore structure of concrete forming carbonic acid, calcium carbonate, through the reaction of $\mathrm{CO}_{2}$ and concrete constituents. This then attacks calcium-containing constituents of calcium-silica-hydrates (C-S-H) and calcium aluminosilicate (C-A-S-H). As a consequence, the calcareous matter in the concrete is removed resulting in the reduction of $\mathrm{pH}$ from around 12 to below 9 . This then leads to reduction in the alkalinity of the concrete that results in the corrosion of steel rebar and reduces the performance reinforced concrete. The results of carbonation depth of both design strength concretes are given in Figures 8(a) and 8 (b) respectively. It can be seen from the results that carbonation depth increases as the exposure period increases. The results also revealed that carbonation depth increased significantly as the replacement level of additional cementitious constituents increased. The increase in carbonation depths is in agreement with previous studies that replacing PC with additional cementitious constituents $[7,13,16,18]$ reduces $\mathrm{CH}$ content available in the pore structure due to its consumption by the pozzolanic reaction in cementitious system. Moreover, results were coherent with Hui-sheng [7] that GGBS is more active additional cementitious constituent compared to FA, thus activation of pozzolanic reaction leads to lower $\mathrm{CH}$ content and provide denser matrix concrete. This phenomenon can also be supported by the relationship between the carbonation depths at the end of the exposure period and compressive cube strengths at 365 days weeks as shown in Table 6. The carbonation penetration was observed to increase as the compressive cube strength increased. In addition, it was observed that the carbonation depths increased as the loss of workability over time increased. This is coherent with Akçaözoğlu and Atiş [4]. It may be attributed to the fact that reduction in workability over time has lead in more porous structure, thus facilitating the penetration of $\mathrm{CO}_{2}$, as $\mathrm{CO}_{2}$ diffuses into concrete through the pore structure. However, this contradictory permeation results for ISAT-10 and carbonation resistance tests could be due to different variations in pore structure of concrete between the concrete surface and other parts of the concrete. It is also noteworthy to mention that the test samples for carbonation test were taken out from the provided water curing condition at 28 days and left to air dry for 14 days which might also affect concrete pore structure. 
a)

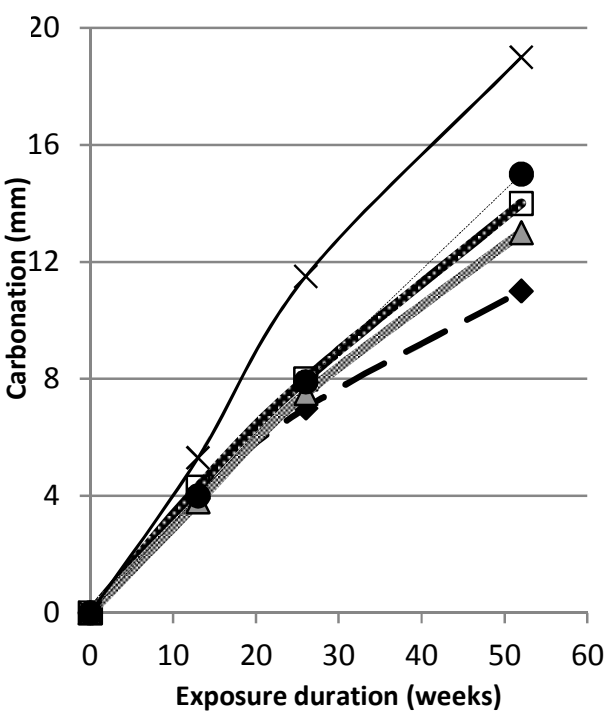

b)

28-day design strength: $50 \mathrm{~N} / \mathrm{mm}^{2}$

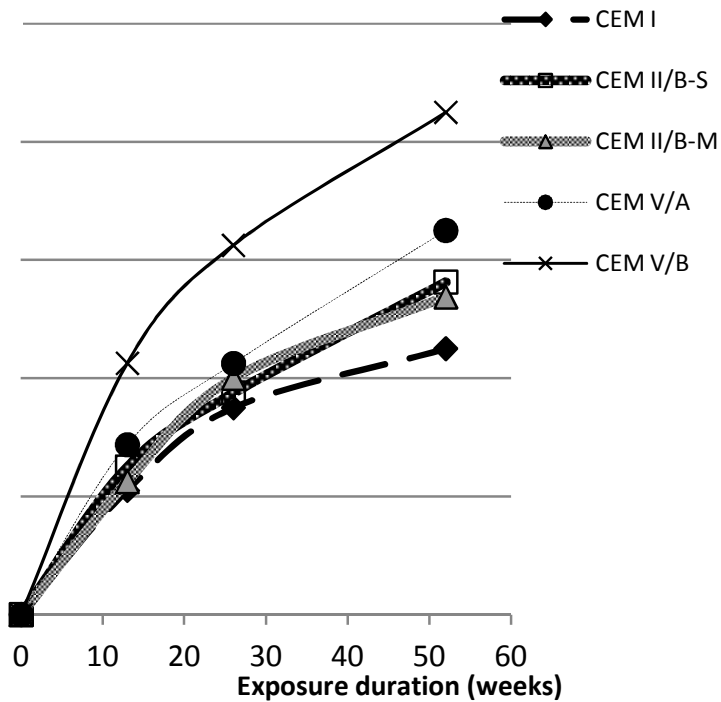

Figure 8. Carbonation depths of equal design strength concrete mixes

Table 6. The relationship between 365 days compressive cube strength and carbonation depth of concretes at the end of exposure period

\begin{tabular}{cccc}
\hline Cement & Design strength & $\begin{array}{c}\text { Compressive cube } \\
\text { strength }\left(\mathbf{N} / \mathbf{m m}^{2}\right)\end{array}$ & $\begin{array}{c}\text { Carbonation depth } \\
(\mathbf{m m})\end{array}$ \\
\hline CEM I & $40 \mathrm{~N} / \mathrm{mm}^{2}$ & 53 & 11 \\
& $50 \mathrm{~N} / \mathrm{mm}^{2}$ & 64 & 9 \\
\hline CEM II/B-S & $40 \mathrm{~N} / \mathrm{mm}^{2}$ & 57 & 14 \\
& $50 \mathrm{~N} / \mathrm{mm}^{2}$ & 67.5 & 11.25 \\
\hline CEM II/B-M & $40 \mathrm{~N} / \mathrm{mm}^{2}$ & 54.5 & 13 \\
& $50 \mathrm{~N} / \mathrm{mm}^{2}$ & 67 & 10.75 \\
\hline CEM V/A & $40 \mathrm{~N} / \mathrm{mm}^{2}$ & 56.5 & 15 \\
& $50 \mathrm{~N} / \mathrm{mm}^{2}$ & 66 & 13 \\
\hline CEM V/B & $40 \mathrm{~N} / \mathrm{mm}^{2}$ & 61 & 19 \\
& $50 \mathrm{~N} / \mathrm{mm}^{2}$ & 66 & 17 \\
\hline
\end{tabular}

\section{PRACTICAL IMPLICATIONS}

For the aim this research, adjustments depending upon the additional cementitious constituents used were made including total binder content and free water content, thereby $\mathrm{w} / \mathrm{c}$ ratio. The use of GGBS and SF in Portland-slag and composites cement concretes were observed to be an effective approach in reducing total cementitious constituents for a given design strength which could potentially reduce by-products from other industries, such as FA and GGBS, for use in the cement being sent to landfill as well as the use of PC in concrete production which is the main contributor of concrete $\mathrm{CO}_{2}$ emissions. Therefore, the approach adopted here could encourage the concrete industry to produce more environmentally friendly and economically viable concretes by these cements in concrete production. 
As far as the fresh properties is concerned, substituting PC content under a certain level is not a practical approach due to the use of Portland-slag and composites cements at higher replacement levels can increase the loss of workability over time. However, this would be disregarded with the reduced casting time.

For engineering properties, the use of Portland slag and composites cement concretes is not a practical approach as far as fast track construction is concerned. This may require the longer period for formwork to be removed or otherwise, developed concretes may be used for non-load bearing application where early strength is not of a concern. Considering Portland-slag and composites cement concretes had higher strength developments, these concretes can be practically applicable if cured adequately until pozzolanic reaction takes place. On the other hand, compressive cylinder results indicated that use of $40 \mathrm{~N} / \mathrm{mm}^{2}$ design strength CEM II/B-M cement concretes may be used in structural members under compression. Similar to compressive strength performance, the use of Portland-slag and composites cements could practically be used in concrete beam members if early strength is not of a concern and supported with appropriate formwork until the pozzolanic reaction takes place to compensate early strength loss. Moreover, the use of Portland-slag and composites cements is observed to be a practical solution for concrete slab construction. With reduced drying shrinkage, this could prevent cracking formation in comparison to CEM I cement concretes.

From the durability point of view, Portland-slag and composites cement concretes with improved permeability can be used where concrete surface is exposed to hazardous chemicals. However, the carbonation test results of this research showed that the use of these cements in structural concrete members could potentially lead to corrosion of reinforcing bars due to reduced alkalinity of Portland-slag and composites cement concretes.

\section{CONCLUSIONS}

The results obtained in this research provide technical information on the engineering and durability performances of concretes made with Portland-slag and composites cements. The main conclusions could be drawn are stated below:

- Portland-slag and composites cement concretes were observed to reduce workability over time significantly due to having lower w/c ratios. Workability of mixes over time was reduced as the replacement level increased. Use of Portland-slag (CEM II/B-S) cements with the highest PC content amongst Portland-slag and composites cements provided comparable or slightly lower concrete workability over time whilst composite cement, CEM V/B, mixes with the lowest PC content reduced workability over time remarkably. FA addition in composite cement concretes increased the viscosity of concrete indicated lower workability over time despite the fact GGBS has better dispersion and smooth and dense surface characteristics.

- Use of Portland-slag and composites cements reduced concrete compressive cube strength significantly at early ages. The strength reduction in Portland-slag and composites cement mixes increased as the PC was substituted with the additional cementitious constituents. Thus, CEM V/B cement concretes resulted in significant early strength loss than CEM II and CEM V/A cement concretes. This lower early 
strength performance is due to the fact that $\mathrm{FA}$ addition reduced $\mathrm{CaO}$ content significantly for the formation of $\mathrm{C}-\mathrm{S}-\mathrm{H}$ gel even though presence of GGBS had higher $\mathrm{CaO}$ in its composition. The contribution of pozzolanic reactions to strength was observed to take place between 7 and 28 days. CEM II and CEM V cement concretes achieved higher compressive cube strengths compared to conventional mix at post 28-days. Similar trends were reported for compressive cylinder and flexural strengths.

- Portland-slag and composites cement mixes indicated lower $f_{\text {cyy }} / f_{\text {cube }}$ ratios than design factor of 0.8 . However, the results were in line with previous studies. In addition, similar trend as compressive cube strength development was observed for flexural strength development for Portland-slag and composites cement concretes.

- Portland-slag and composites cement concretes resulted in higher shrinkage development at 7 days which is believed to be due to slag delays the hydration reaction between the cement paste and water, thus free water content contributes to early shrinkage development. Portland-composite cement (PC+GGBS+SF) concrete was observed to compensate the anticipated adverse effect of SF on the drying shrinkage development. At post 7 days, Portland-slag and composites cement mixes reduced the shrinkage strain dramatically in comparison to control mix CEM I.

- Test examining durability including ISAT and carbonation showed that Portland-slag and composites mixes have superior permeation property but lower resistance to carbonation comparing to conventional CEM I cement concretes under adequate curing conditions. Portland-slag and composites cements were investigated to refine the pore structure of concretes. However, reducing PC content was observed to reduce resistance to carbonation considerably. Thus, Portland-slag and Portlandcomposite cement concretes with higher PC content indicated higher resistance to carbonation compared to other composite cement concretes. It was also observed that carbonation penetration decreased as the compressive cube strength increased except CEM I mixes. Also, it was found out that resistance to carbonation was significantly linked with loss of workability over time.

- The practical implications of the research have been investigated and indicate the technical information for the concrete construction including engineering and durability properties of concretes made with Portland-slag and composites cement concretes. There is a potential to use these cements carbon efficient environmentally friendly and economically viable concrete production in construction industry. However, Portland-slag and composites cement concretes can be used in concrete members where early strength is not an essential parameter. In general, these concretes provided improved long-term strength, drying shrinkage and surface permeation properties whilst reduced carbonation resistance. Therefore, these concretes can be used in conditions where impermeable concrete surfaces are required. Given these, there is a potential to use these concretes in structural applications, however further investigation is necessary on the corrosion resistance of concrete as reduced carbonation resistance could lead to corrosion of concrete reinforcement. 


\section{Acknowledgement}

The authors would like to acknowledge Hanson UK, Elkem AS and Grace Construction Products Ltd. for providing the materials for the presented work.

\section{References}

1- British Standard Institution. BS EN 197-1 Cement. (2011) Composition, specifications and conformity criteria for common cements. BSI. London.

2- Megat Johari, M.A., Brooks, J.J., Kabir, S. and Rivard, P. (2011) Influence of supplementary cementitious on engineering properties of high strength concrete. Construction and Building Materials 25 (5), pp.2639-2648.

3- Teng, S., Lim, T.Y.D. and Divsholi, B.S. (2013) Durability and mechanical properties of high strength concrete incorporating ultra fine Ground Granulated Blast-furnace Slag. Construction and Building Materials 40, pp.875-881.

4- Akçaözoglu, S. and Atiş, C.D. (2011) Effect of Granulated Blast Furnace Slag and fly ash addition on the strength properties of lightweight mortars containing waste PET aggregates. Construction and Building Materials. 25 (10), pp.4052-4058.

5- Erdem, T.K. and Kirca, O. (2008) Use of binary and ternary blends in high strength concrete. Construction and Building Materials, 22, pp.1487-1493.

6- Khatri, R., Sirivivatnanon, V. and Gross, W. (1995) Effect of different supplementary cementitious materials on mechanical properties of high performance concrete. Cement and Concrete Research. 25 (1), pp.209-20

7- Hui-sheng, S., Bi-wan, X. and Xiao-chen, Z. (2009) Influence of mineral admixtures on compressive strength, gas permeability and carbonation of high performance concrete. Construction and Building Materials. 29, pp.1985-1990.

8- Guneyisi, E., Gesoglu, M. and Ozbay, E. (2010) Strength and drying shrinkage properties of self-compacting concretes incorporating multi-system blended mineral admixtures. Construction and Building Materials. 24, pp.1878-1887.

9- Kuder, K., Lehman, D., Berman, J., Hannesson, G. and Shogren, R. (2012) Mechanical properties of self consolidating concrete blended with high volumes of fly ash and slag. Construction and Building Materials 34, pp.285-95.

10- Oner, A. and Akyuz, S. (2007) An experimental study on optimum usage of GGBS for the compressive strength of concrete. Cement \& Concrete Composites 29, pp.505-14.

11- Li, G. and Zhao, X. (2003) Properties of concrete incorporating fly ash and ground granulated blast-furnace slag. Cement \& Concrete Composites 25, pp.293-99.

12- Berndt, M.L. (2009) Properties of sustainable concrete containing fly ash, slag and recycled concrete aggregate. Construction and Building Materials. 23, pp.2606-2613.

13- Qiang, W., Peiyu, Y., Jianwei, Y. and Bo, Z. (2013) Influence of steel slag on mechanical properties and durability of concrete. Construction and Building Materials. 47, pp.1414-1420.

14- Gesoğlu M., Guneyisi, E. and Ozbay, E. (2009) Properties of self-compacting concretes made with binary, ternary, and quaternary cementitious blends of fly ash, blast furnace slag, and silica fume. Construction and Building Materials 23 (5), pp.1847-54.

15- Jianyong, L. and Yan, Y. (2001) A study on creep and drying shrinkage of high performance concrete. Cement and Concrete Research 31, pp.1203-06. 
16- Jones, M.R., Dhir, R.K. and Magee, B.J. (1997) Concrete Containing Ternary Blended Binders: Resistance to Chloride Ingress and Carbonation. Cement and Concrete Research 27 (6), pp.825-31.

17-Bernal, S.A., de Gutiérrez, R.M., Pedraza, A.L., Provis, J.L., Rodriguez, E.D. and Delvasto, S. (2011) Effect of binder content on the performance of alkali-activated slag concretes. Cement and Concrete Research 41, pp.1-8.

18-Song, H. and Saraswathy, V. (2006) Studies on the corrosion resistance of reinforced steel in concrete with ground granulated blast-furnace slag - an overview. Journal of Hazardous Materials B138, pp.226-33.

19- Younsi, A., Turcry, Ph., Aït-Mokhtar, A. and Staquet, S. (2013) Accelerated carbonation of concrete with high content of mineral additions: Effect of interactions between hydration and drying. Cement and Concrete Research 43, pp.25-33.

20-Borges, P.H.R., Costa, J.O., Milestone, N.B., Lynsdale, C.J. and Streatfield, R.E. (2010) Carbonation of $\mathrm{CH}$ and $\mathrm{C}-\mathrm{S}-\mathrm{H}$ in composite cement pastes containing high amounts of BFS. Cement and Concrete Research 40, pp.284-92.

21-British Standard Institution. BS EN 15167 - Ground granulated blast furnace slag for use in concrete, mortar and grout. Definitions, specification and conformity criteria. BSI. London.

22-British Standard Institution. BS EN 450-1 Fly ash for concrete. (2012) Definition, specifications and conformity criteria. BSI. London.

23- British Standard Institution. BS EN 13263-1:2005+A1:2009 Silica fume for concrete. (2005) Definitions, requirements and conformity criteria. BSI. London.

24- British Standard Institution. BS EN 934-2:2009+A1:2012 Admixtures for concrete mortar and grout. (2009) Concrete admixtures. Definitions, requirements, conformity, marking and labelling. BSI. London.

25- Building Research Establishment Ltd. (1997) Design of normal concrete mixes. $2^{\text {nd }}$ ed., London: Construction Research Communications Ltd.

26- British Standards Institution. BS EN 12350-2 Testing fresh concrete. (2009) Slump test. BSI. London.

27- British Standards Institution. BS EN 12390-2 Testing hardened concrete. (2009) Making and curing specimens for strength tests. BSI. London.

28- British Standards Institution. BS ISO 1920-8 Testing hardened concrete. (2009) Determination of the drying shrinkage of concrete for samples prepared in the field or in the laboratory.

29- British Standard Institution. BS 1881-208 Testing concrete. (1996). Recommendations for the determination of the initial surface absorption of concrete. BSI. London.

30-British Standard Institution. BS 1881-210 Testing hardened concrete. (2013) Determination of the potential carbonation resistance of concrete - Accelerated carbonation method. BSI. London.

31- British Standard Institution. BS EN 206-1 Concrete. (2013) Specification, performance, production and conformity.

32- McCarthy, M.J. and Dhir, R.K. (2005) Development of high volume fly ash cements for use in concrete construction. Fuel. 84 (11), pp.1423-32.

33- Gönen, T. and Yazicioglu, S. (2007) The influence of mineral admixtures on the short and long-term performance of concrete. Building and Environment. 42 (8), pp.3080-85.

34- Bhanja, S. and Sengupta, B. (2002) Investigations on the compressive strength of silica fume concrete using statistical methods. Cement and Concrete Research. 32, pp.139194. 
35- Nikbin, I.M., Dehestani, M., Beygi, M.H.A. and Rezvani, M. (2014) Effects of cube size and placement direction on compressive strength of self-consolidating concrete. Construction and Building Materials. 59, pp.144-150.

36-Limbachiya, M., Meddah, M.S. and Ouchagour, Y. (2012) Use of recycled concrete aggregate in fly-ash concrete. Construction and Building Materials, 27, pp.439-449. 